\title{
MicroRNA-122a Regulates Zonulin by Targeting EGFR in Intestinal Epithelial Dysfunction
}

\author{
Bin Zhang ${ }^{a}$ Yinghai Tiang Ping Jiang ${ }^{c}$ Yanqiong Jiang ${ }^{d}$ Chao Lie Ting Liu ${ }^{b}$ \\ Rujian Zhou ${ }^{b}$ Ning Yang $^{b}$ Xinke Zhou ${ }^{b}$ Zhihua Liub,e,f
}

\begin{abstract}
aDepartment of Neurology, Shanghai Jiao Tong University Affiliated Sixth People's Hospital, Shanghai, bDepartment of Center Laboratory, the Fifth Affiliated Hospital of Guangzhou Medical University, Guangzhou, 'Department of Paediatrics, the Fifth Affiliated Hospital of Guangzhou Medical University, Guangzhou, dDepartment of Clinical laboratory, the Fifth Affiliated Hospital of Guangzhou Medical University, Guangzhou, eDepartment of Colorectal Surgery, the Sixth Affiliated Hospital of Sun Yat-Sen University, Guangzhou, fDepartment of AnoRectal Surgery, the Fifth Affiliated Hospital of Guangzhou Medical University, Guangzhou, 9Department of Emergency, the Fifth Affiliated Hospital of Guangzhou Medical University, Guangzhou, China
\end{abstract}

\section{Key Words}

MicroRNA-122a • Intestinal barrier • EGFR • Zonulin

\begin{abstract}
Background/Aims: This study aimed to investigate the role of microRNA (miR)-122a in regulating zonulin during the modulation of intestinal barrier. Methods: Zonulin proteins and their target gene expression were analyzed in miR-122a-overexpressing cell lines and in the target gene of epidermal growth factor receptor (EGFR). An mmu-miR-122a intestinal epithelial conditional transgenic (miR-122a-TG) mouse model was established to investigate EGFR and zonulin expression. MiR-122a was also detected in the clinical specimens of inflammatory bowel disease. Results: EGFR was identified as a target gene of miR-122a. The expression level of miR-122a was positively correlated with that of zonulin. The expression level of zonulin was significantly increased, whereas the expression level of EGFR was significantly decreased in the miR-122a-TG mice and in the corresponding primary epithelial culture $(P<0.05)$. These results were consistent with the data of the clinical specimens. Conclusions: miR-122a could be a positive factor of zonulin by targeting EGFR, which increased the intestinal epithelial permeability in vivo and in vitro.

(C) 2017 The Author(s)

Published by S. Karger AG, Basel
\end{abstract}

\section{Introduction}

MicroRNAs (miRNAs, miRs) act as negative regulators of gene translation through the inhibition of mRNA translation or promotion of mRNA degradation by binding to their B. Zhang, Y. Tian and P. Jiang are co-first authors.

Dr. Zhihua Liu, MD, PhD and Dr. Xinke Zhou, MD, PhD

KARGER
Department of AnoRectal Surgery, the Fifth Affiliated Hospital of Guangzhou Medical University, Guangzhou, Guangdong, 510799, (China); Department of Center Laboratory the Fifth Affiliated Hospital of Guangzhou Medical University, Guangzhou, Guangdong, 510799, (China); E-Mail liuzhihualzh@hotmail.com / xkzhou12@outlook.com 
3 '-untranslated regions (3'-UTRs) [1]. MiRNAs can participate in the regulation of gene expression in various critical biological processes, such as development, differentiation, apoptosis, and proliferation [2] Changes in miRNA expression are also associated with many diseases, including cancers [3-5], heart diseases [6], nervous system disorders, and intestinal barrier dysfunction $[1,7,8]$.

The relationship between miRNAs and intestinal epithelial barrier dysfunction has been rarely investigated [1, 7-11]. McKenna et al. determined the complete miRNA expression profile of the mammalian intestinal mucosa and the contribution of miRNAs to intestinal homeostasis by using Dicer $1^{\text {loxp } / \text { loxp: }}$ Villin-Cre mutant mice and found a decrease in the expression of all miRNAs [11]. Intestinal barrier function is impaired in Dicer1-deficient mice and thus causes intestinal inflammation with lymphocyte and neutrophil infiltration. Tumor necrosis factor alpha (TNF)- $\alpha$ can rapidly increase the expression of miR-122a in enterocytes, cultured cells, and intestinal tissues and consequently induce occludin mRNA degradation and increase intestinal permeability [11]. Zonulin is a protein found in tight junctions in the intestinal tract and secreted by the cholera pathogen Vibrio cholerae, which was initially discovered in 2000 as the target of zonula occludens toxin [12]. Zonulin is also an indicator of intestinal permeability $[12,13]$.

The relationship between miR-122a and zonulin expression levels has also been explored. We hypothesized that miR-122a can help protect intestinal barrier functions by regulating zonulin. We aimed to investigate the molecular mechanisms of miR-122a in zonulin regulation by targeting the epidermal growth factor receptor (EGFR).

\section{Materials and Methods}

\section{Cell culture}

Caco-2 cells purchased from ATCC (Manassas, VA) were grown under standard cell culture conditions and grown in Dulbecco's modified Eagle's medium supplemented with $10 \%$ fetal bovine serum, $100 \mathrm{U} / \mathrm{ml}$ of penicillin, and $100 \mu \mathrm{g} / \mathrm{ml}$ of streptomycin at $37^{\circ} \mathrm{C}$ in a humidified atmosphere containing $5 \% \mathrm{CO}_{2}$. The cells were passaged at pre-confluent densities using $0.05 \%$ trypin and $0.5 \mathrm{~mm}$ of ethylenediaminetetraacetic acid (Gibco, USA), as previously described. For different groups, $5 \mu \mathrm{g} / \mathrm{mL}$ of lipopolysaccharide (LPS) (24 h) with dimethyl sulfoxide (DMSO) $(48 \mathrm{~h})$ was added for the treatment group, whereas phosphate-buffered saline (PBS) (24 h) with DMSO (48 h) was added for the control group.

Transfection of miR-122a overexpression lentivirus

The hsa-miR-122a cDNA was amplified by RT-PCR with human genomic DNA using $5^{\prime}$-TGGAGTGTGACAATGGTGTTTGT- $3^{\prime}$ and $3^{\prime}$-ACCTCACACTCTTACCACAAACA-5'. The 5'- and 3 '-primers contained BamH I and Xho I sites, respectively, as indicated by underlines. The amplified cDNA was inserted into the BamH I and Xho I sites of a mammalian expression plasmid vector, PGIP2 (Promega), at a site downstream of the cytomegalo virus promoter. Recombinant plasmid DNA was purified with a Qiagen plasmid kit (Qiagen, Valencia, CA, USA) and used to transfect NCM460 cells. The insert orientation was confirmed by sequencing. After transfection was performed using Tfx-50 reagent (Promega), the cells were cultured in the presence of G418, and the G418-resistant colonies were collected 2 weeks later. Cell clones were expanded individually, and clones expressing high levels of hsa-miR-122a on their surface were selected by flow-cytometric analysis with SN2Ab. A clone (designated as H11-SN2) that expressed hsa-miR122a on the cell surface at a similar level to that of NCM460 cells was used in this study [14].

Building and identifying miR-122a transgenic mice

MiR-122a intestinal transgenic mice (mir-122a-TG) were generated by Cyagen Biosciences Inc. (Guangzhou, China) using a villin promoter and background mice of C57BL/6, as described [15]. Mice were bred and kept at the Sun Yat-Sen University Laboratory Animal Center (Guangzhou, China). All of the mice were raised under specific pathogen-free conditions with filtered air, fed rodent chow ad libitum, and allowed free access to water. Genotyping of mice was performed by PCR using genomic DNA isolated from the tail by

\section{KARGER}




\section{Cellular Physiology Cell Physiol Biochem 2017;42:848-858 \begin{tabular}{l|l} 
and Biochemistry Published 10.1159/000478629 2017 & $\begin{array}{l}\text { (c) } 2017 \text { The Author(s). Published by S. Karger AG, Basel } \\
\text { www.karger.com/cpb }\end{array}$
\end{tabular} \\ Published onlıne: June 23, 2017 www.karger.com/cp}

the tissue DNA isolation kit (Biomiga, China). Animal studies were approved by the Animal Care Committee of the Sun Yat-Sen University. Mice were sacrificed at 8 weeks for determination. The concentrations of serum zonulin $24 \mathrm{~h}$ postoperatively were measured by using an enzyme-linked immunosorbent assay (ELISA) kit, as previously described [12].

\section{Isolation of intestinal epithelium and primary colon cell culture}

The proximal and distal cecum and colon were opened along their vertical axis, and their luminal contents were removed by washing the tissues in PBS. Each segment was placed in Hanks' buffered saline solution (HBSS) containing $25 \mathrm{mM}$ of 4-(2-hydroxyethyl)-1-piperazineethanesulfonic acid and 1\% calf serum (Sigma) (three washes of 5 min each, $20 \mathrm{ml} /$ wash). RNA was isolated (RNeasy kit, Qiagen) from the cell pellets (epithelial fraction) and the remaining tissue fragments (mesenchymal fraction) [16]. The primary cell culture of mir-122a-TG colon was performed as described [17].

\section{Patients}

Colon tissues were obtained from the surgical specimens of patients with inflammatory bowel disease (IBD) admitted for the operation. Blood samples were collected and stored properly. Clinical research was approved by the ethical committee of the Sixth Affiliated Hospital of Sun Yat-Sen University and the Fifth Affiliated Hospital of Guangzhou Medical University. Informed consents were obtained from the patients.

\section{Luciferase assay}

The resulting fragments containing intact putative miR-122a recognition sequences from the $3^{\prime}$-UTR or with random mutations were cloned in the psi-CHECK2 vector (Promega), as previously described. Caco2 cells were cotransfected using Transit-TKO (Invitrogen) with the reporter plasmids and either the wild type (WT) or mutant vector. Luciferase assays were performed $48 \mathrm{~h}$ post-transfection following the protocol of the manufacturer (Dual-luciferase reporter assay system, E1910; Promega). The luciferase activities were measured with a Dual-Luciferase Report System (Promega).

\section{RNA isolation}

Total RNA was extracted from cells or tissue samples using Trizol lysis buffer (Ambion, USA) according to the instructions of the manufacturer. The microRNA isolation of cell or tissue or serum samples was performed with miRNeasy Mini Kit (Qiagen, Germany) according to the instructions of the manufacturer.

\section{Quantitative real-time PCR ( $q R T$-PCR) analysis}

First strand synthesis of cDNA was performed with the Reverse Transcription Kit (Invitrogen, USA). A qRT-PCR for mRNA was performed using SYBR Master Mix (Invitrogen, USA) according to the instructions of the manufacturer and using a 7,500 Real-Time PCR system. First strand synthesis of cDNA was also performed with TaqMan MicroRNA Reverse Transcription Kit (ABI, USA). A qRT-PCR for microRNA was performed using TaqMan microRNA Assay (ABI, USA).

The qRT-PCR primer sequences were as follows:

EGFR: (F) 5'-ATGGTCAAGTGCTGGATG-3', (R) 5'-GAGGAAGGTGTCGTCTATG-3'

Zonulin: (F) 5'-TCATCACGGCGCGCCAGG-3', (R) 5'-GGAGGTCTAGAATCTGCCCGAT-3'

Interleukin (IL)-6: (F) 5'-CCAGAAGACCAGAGGAAA-3', (R) 5'-GGAAATCGTGGAAATGAG-3'

TNF- $\alpha$ : (F) $5^{\prime}$-GACGTGGAACTGGCAGAAGAG-3', (R) 5'-TTGGTGGTTTGTGAGTGTGAG-3'

Occludin: (F) 5'-TTGAAAGTCCACCTCCTTACAGA-3'; (R) 5'-CCGGATAAAAAGAGTACGCTGG-3'

CLDN-1: (F) 5'-CTTCAGCAGACGAAGGTT-3', (R) 5'-CATAGGCAGGACAAGAGTTA-3'.

\section{Western blot analysis}

For Western blotting, proteins were separated on sodium dodecyl sulfate-polyacrylamide gel electrophoresis gels and then transferred to polyvinylidene difluoride membranes (Millipore, Massachusetts) using a wet electroblotter (Bio-Rad) for $120 \mathrm{~min}$ at $100 \mathrm{~V}$. The membrane was then incubated with the appropriate primary antibody at $4^{\circ} \mathrm{C}$ overnight, washed three times (10 min each time) with Tris-buffered saline (TBS) containing $0.1 \%$ Tween 20 (TBS-T buffer), and then incubated for $1 \mathrm{~h}$ with the appropriate horseradish peroxidase-conjugated secondary antibody in TBS-T buffer for $4 \mathrm{~h}$ at $4^{\circ} \mathrm{C}$. The membrane was washed three times ( $60 \mathrm{~min}$ each time) with TBS-T buffer and developed by the enhanced chemiluminescence 


\section{Cellular Physiology Cell Physiol Biochem 2017;42:848-858

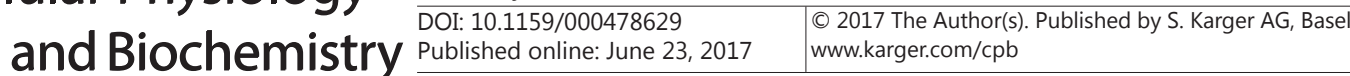 \\ Zhang et al.: MiR-122a, Zonulin and Intestinal Barrier}

method (ECL kit; Pierce, Illinois) according to the instructions of the manufacturer [12]. The antibodies used in our study were anti-occludin antibody (EPR8208, ab167161), anti-claudin 1 antibody (EPRR18871, ab211737), anti-EGFR antibody (EP38Y, ab52894), and anti-haptoglobin antibody (HG-36, ab13429).

\section{Permeability assay}

The measurement of transepithelial electrical resistance (TER) and dextran permeability was described previously [18]. The intestinal epithelial monolayers were divided into five different experimental groups in triplicate. The measurement of the intestinal permeability and colonic damage in mice was performed as previously described [18]. Final data were reported as either the fractional excretion (for sucralose) to determine the colonic permeability or a ratio of fractional excretion (for lactulose/mannitol) to quantify the small intestinal permeability. Fractional excretion was defined as the fraction of the gavage dose recovered in the urine, and the ratio of fractional excretion was defined as the ratio of the fraction of the gavaged dose of lactulose recovered in the urine over the fraction of the gavaged dose of mannitol recovered in the urine. Ussing chamber assay was also used to determine the intestinal permeability measurement in isolated mice colons. Tissue ion resistance $(1 / G$, where $G$ represents the conductance) was calculated from the potential difference and short-circuit current according to Ohm's law [18].

\section{Statistical analysis}

Data were statistically analyzed in GraphPad Prism 5 (San Diego, CA) and expressed as mean \pm SEM. Statistical analysis was performed with paired Student's $t$ test. $\mathrm{P}<0.05$ was defined as significant.

\section{Results}

\section{LPS elicited damaging effects on tight junction}

After LPS treatment was administered, the expression levels of Claudin-1 and occludin were significantly decreased in Caco-2 cells (Fig. $1 \mathrm{~A} \& \mathrm{~B}, \mathrm{P}<0.05$ ), whereas the expression levels of miR-122a and zonulin were increased (Fig. 1 C\&D, P < 0.05). For the expression

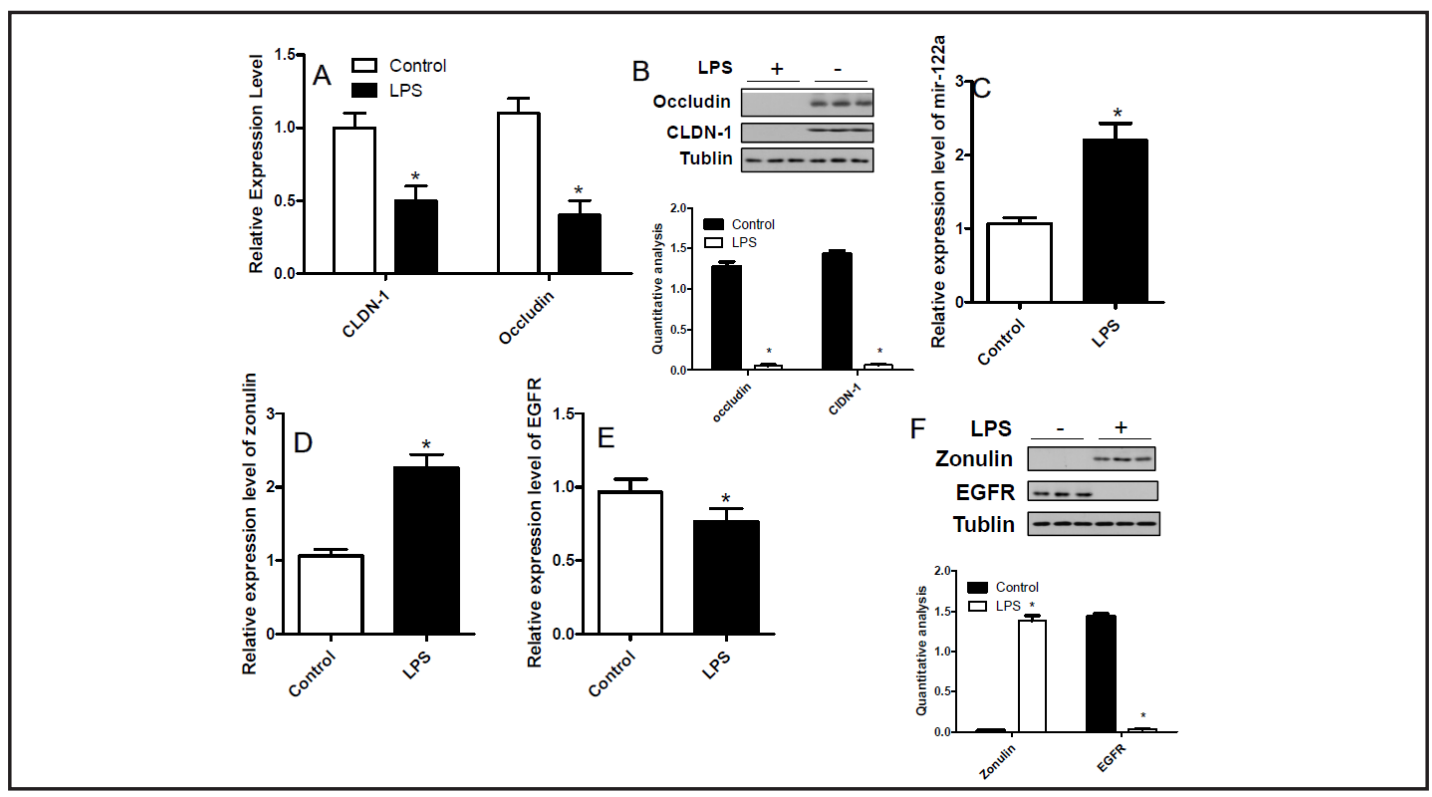

Fig. 1. LPS had jury to intestinal tight junction. (A) LPS could lower the expression level of occluding and Claudin-1 determined by qRT-PCR. (B) LPS could lower the expression level of occluding and Claudin-1 determined by western blot and semi-quantitative analysis. (C) LPS could higher the expression level of miR122a determined by qRT-PCR. (D) LPS could higher the expression level of zonulin determined by qRT-PCR. (E) LPS could not lower the mRNA expression level of EGFR determined by qRT-PCR. (F) LPS could lower the protein expression level of EGFR determined by western blot and semi-quantitative analysis. ${ }^{*} \mathrm{P}<0.05$. Three independent experiments were performed. 


\begin{tabular}{|c|c|c|}
\hline \multirow{2}{*}{$\begin{array}{l}\text { Cellular Physiology } \\
\text { and Biochemistry }\end{array}$} & \multirow{2}{*}{\multicolumn{2}{|c|}{ 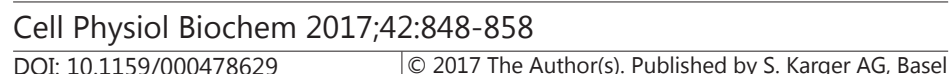 }} \\
\hline & & $\begin{array}{l}\text { o } 2017 \text { The Author(s). Published by S. Karger AG, Basel } \\
\text { wwwwkargercom/cp }\end{array}$ \\
\hline
\end{tabular}

Table 1. Bioinformatics analysis of the score of the target gene of miRNA-21

\begin{tabular}{llc}
\hline Target & \multicolumn{1}{c}{ Function of target gene } & score \\
\hline EGFR & epidermal growth factor receptor & 88 \\
BCAT2 & branched chain amino-acid transaminase 2, mitochondrial & 80 \\
BAI2 & brain-specific angiogenesis inhibitor 2 & 69 \\
GREM2 & gremlin 2 & 78 \\
MMGT1 & membrane magnesium transporter 1 & 68 \\
Tgfbi & transforming growth factor, beta induced, 68kDa & 66 \\
FUNDC2 & FUN14 domain containing 2 & 66 \\
Tiam1 & T-cell lymphoma invasion and metastasis 1 & 50 \\
Reck & reversion-inducing-cysteine-rich protein with kazal motifs & 50 \\
\hline
\end{tabular}

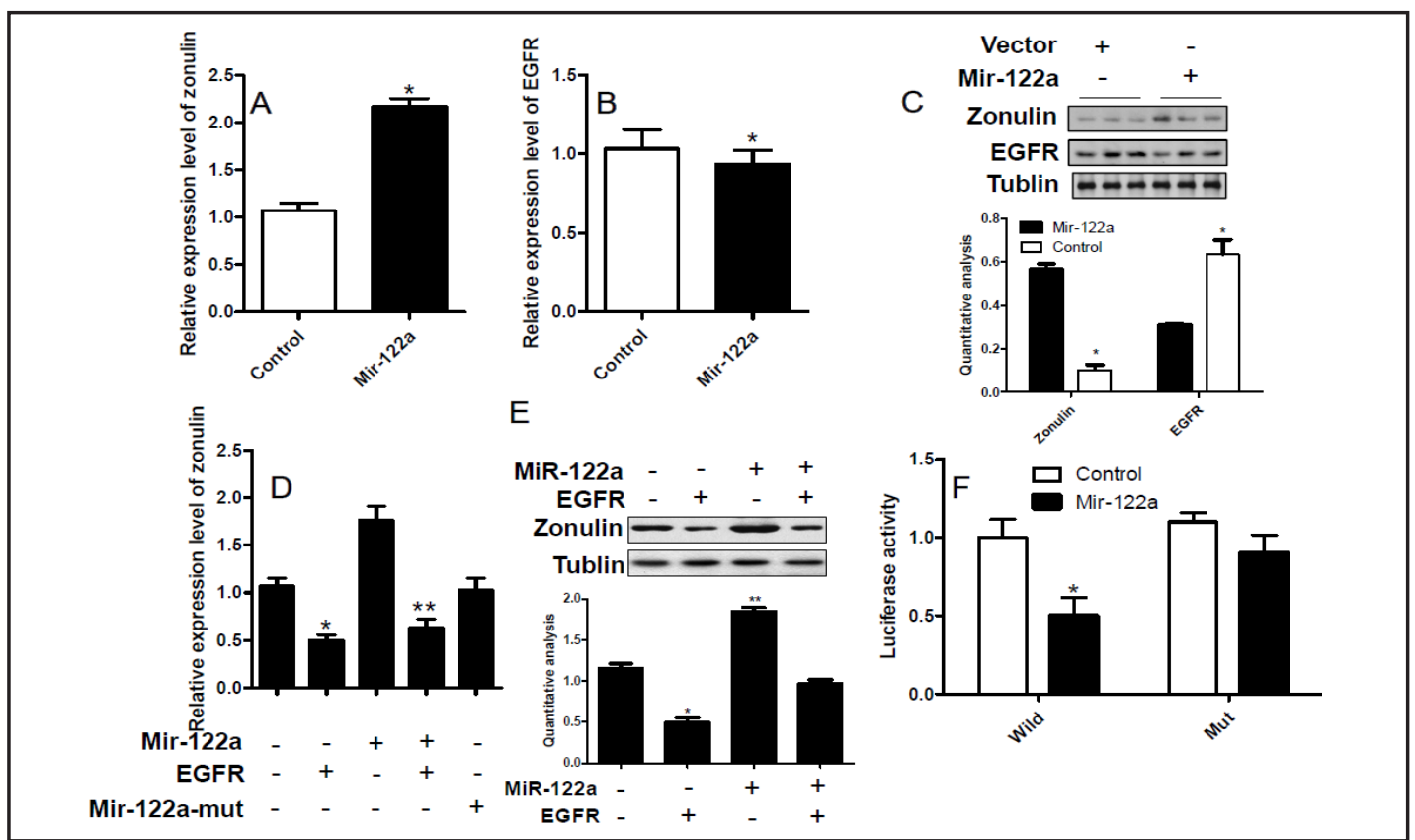

Fig. 2. EGFR could be a target gene of miR-122a. (A) Over-expression of miR-122a increased the expression level of zonulin, while indicated no change of EGFR determined by qRT-PCR (B). (C) Over-expression of miR-122a increased both the expression level of zonulin and EGFR determined by western blot and semi-quantitative analysis. (D, E) Co-overexpression of miR-122a and EGFR showed similar effects on zonulin expression, compared with the single overexpression of EGFR, which covered the effects of miR-122a both at the expression level of mRNA and protein determined by qRT-PCR and western blot and semi-quantitative analysis, whereas just over-expression of miR-122a mutated form indicated no difference with the control. (F) Luciferase assay indicated the target of miR-122a might be the 3'-UTR of EGFR. * P $<0.05$. ** vs *, P > 0.05. Three independent experiments were performed.

level of EGFR, PCR showed an insignificant change (Fig. 1 E, P > 0.05), whereas Western blot showed a significant decrease (Fig. $1 \mathrm{~F}, \mathrm{P}<0.05$ ), which might indicate a post-transcript EGFR regulation, such as miR-122a-induced regulation.

Prediction of EGFR as a miR-122a target

The target miR-122a binding site was predicted using three different computational programs, TargetScan (http://www.targetscan.org/) [19], PicTar (http://pictar.bio.nyu. edu.), [20] and miRanda (http://www.microrna.org/) [21]. After the three lists were generated by the three computational programs, a fourth list was generated, which contained the genes predicted by all the three initial computational programs (Table 1). By the analysis of bioinformatics of MetaCore ${ }^{\mathrm{TM}}$ platform, we selected EGFR as the candidate 


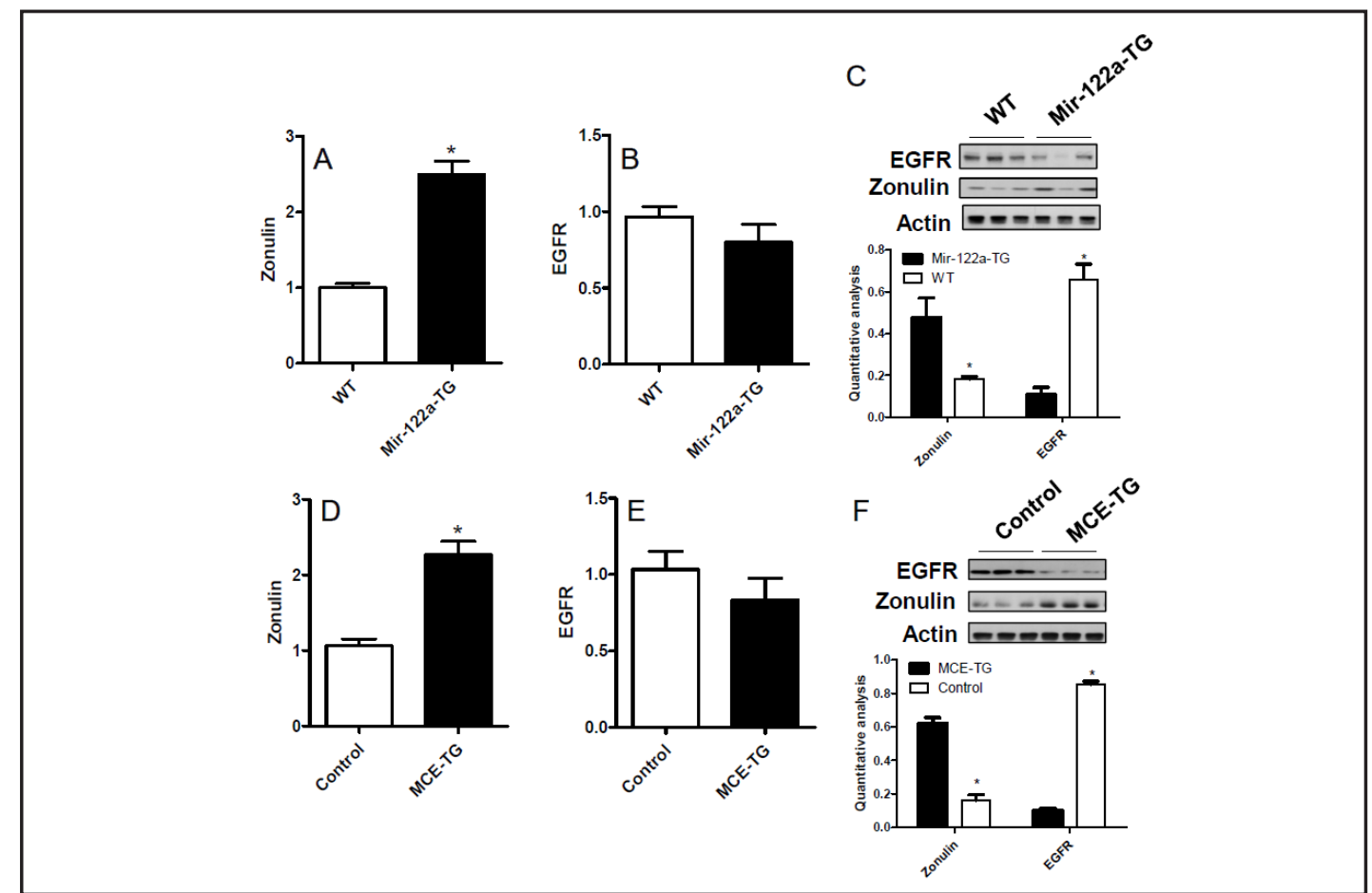

Fig. 3. MiR-122a intestinal transgenic mice got higher expression level of zonulin. (A) MiR-122a-GT mice had an increased intestinal expression level of zonulin determined by qRT-PCR. (B) MiR-122a-GT mice had not a decreased intestinal expression level of EGFR determined by qRT-PCR. (C) MiR-122a-GT mice had a higher expression level of zonulin and a decreased intestinal expression level of EGFR determined by western blot and semi-quantitative analysis. (D, E, F) The primary cell culture showed similar results. ${ }^{*} \mathrm{P}<0.05$. Ten independent experiments were performed.

with the highest score (Table 1), which was reported as a mechanism that might ameliorate intestinal inflammation in mice [22].

We constructed EGFR mRNA 3'UTR vectors (WT and mutant) and inserted them immediately downstream of the luciferase reporter gene to determine whether EGFR was regulated by miR-122a through the direct binding of its 3 '-UTR. In the luciferase assays, the miR-122a precursor or control was co-transfected into the Caco- 2 cells with different $3^{\prime}$-UTR luciferase vectors. The miR-122a significantly decreased the relative luciferase activity in the WT 3'UTR of EGFR ( $<<0.05$, Fig 2F). By contrast, relative luciferase activity did not decrease significantly in the UTRs with mutant-binding sites.

qRT-PCR and Western blot analysis showed that miR-122a could downregulate the expression level of zonulin in Caco-2 cell line transfected with miR-122a precursor (Fig. 2 A\&C, P < 0.05). However, the expression level of EGFR was decreased significantly only in the protein level by Western blot rather than the mRNA level detected by qRT-PCR (Fig. 2 B\&C, P $<0.05)$. Co-transfection of miR-122a and EGFR to Caco-2 cells leading to a similar decrease in zonulin expression to single transfection of EGFR indicated that miR-122a might have EGFRdependent effects on zonulin expression (Fig. 2 D\&E, $P<0.05$ ). However, the overexpression of miR-122a-mutated form had no significant difference from the control (Fig. 2D, P > 0.05).

MiR-122a expression level correlated with the expression level of zonulin

In vivo experiments were also performed in miR-122a-TG mice to determine the effects of miR-122a on intestinal barrier. The colon tissues were performed for qRT-PCR and Western blot. The expression level of zonulin was more significantly increased in miR122a-TG mice than in the WT group both detected by qRT-PCR and Western blot, consistent with the outcomes in Caco-2 cell line, as reported above (Fig. 3A\&C). On the contrary, the 

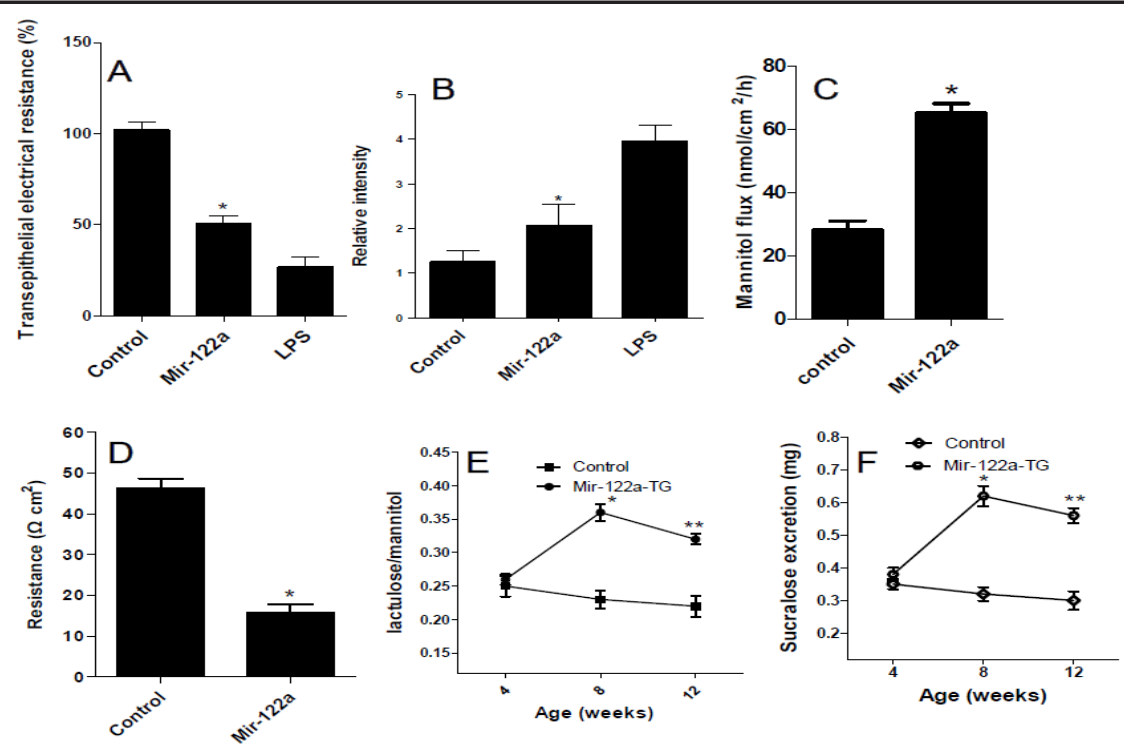

Fig. 4. MiR-122a might lead to a higher intestinal permeability. (A) Transepithelial electrical resistance was lowered after the miR-122a overexpression in Caco- 2 cells. (B) The relative intensity was enhanced after the miR-122a overexpression. (C) Mannitol flux was increased in the miR-122a-TG group mice, compared with the control wild-type group. (D) The resistance was decreased in the miR-122a-TG group mice, compared with the control wild-type group. (E) The lactulose/mannitol rate was higher in the miR-TG group, compared with the control WT group at 4 at 8 , and 12 week mice. (F) The Sucralose excretion was higher in the miR-122a-TG group, compared with the control WT group at 4 at 8 , and 12 week mice in vivo. ${ }^{*} \mathrm{P}<0.05$, ${ }^{* *}$ $\mathrm{P}<0.05$. Three independent experiments were performed for cell test, and ten were performed for mice.
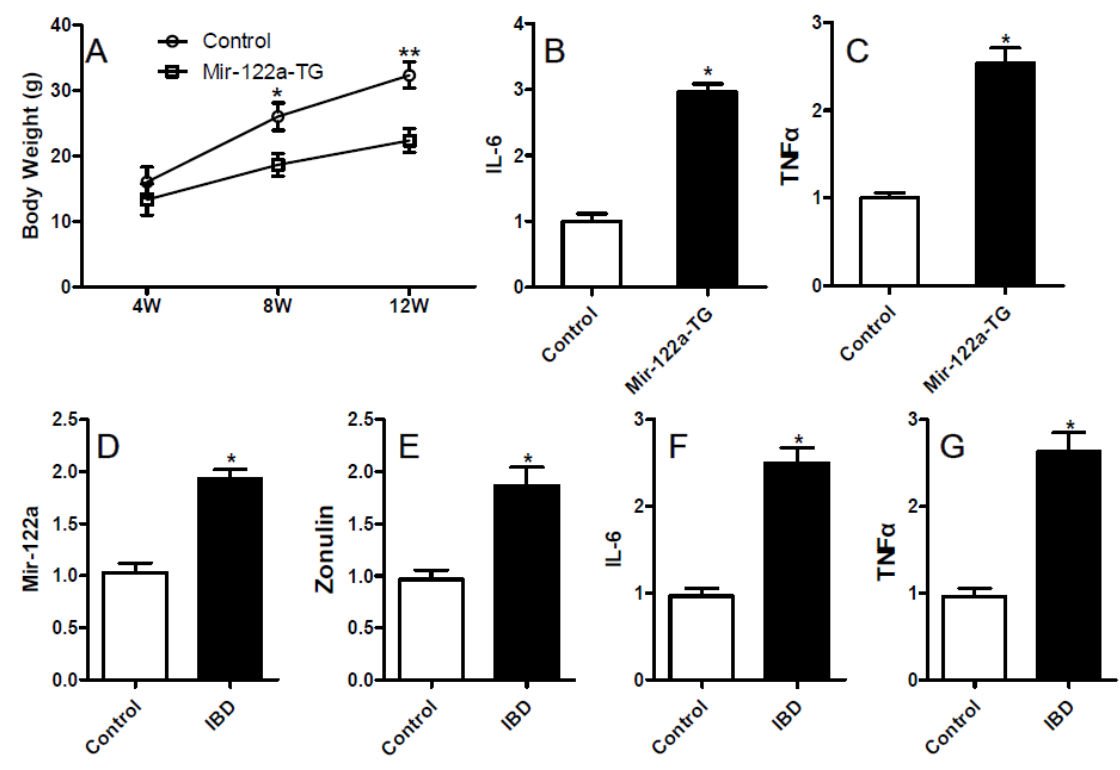

Fig. 5. MiR-122a might cause the intestinal inflammation. (A) Body weight of miR-122a-TG mice was lower at 8 , and 12 weeks mice. (B, C) IL-6 and TNF- $\alpha$ levels were higher in the miR-122a-TG mice, compared with the WT group in mice blood. (D, E) The expression level of miR-122a and zonulin was higher in the inflammatory bowel disease patients, compared with the control volunteer group in the colon tissues. (F, G) IL-6 and TNF- $\alpha$ levels were higher in the inflammatory bowel disease patients, compared with the control volunteer group in the blood. ${ }^{*} \mathrm{P}<0.05,{ }^{* *} \mathrm{P}<0.05$. Ten independent experiments were performed. 


\section{Cellular Physiology Cell Physiol Biochem 2017;42:848-858

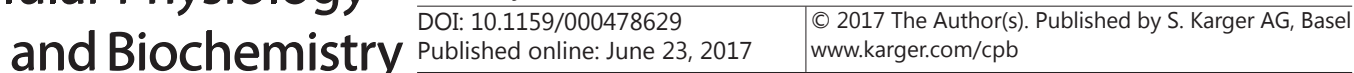 \\ Zhang et al.: MiR-122a, Zonulin and Intestinal Barrier}

expression level of EGFR was decreased more significantly in miR-122a-TG mice than in the WT group only detected by Western blot (Fig. 3B\&C). Similar results were indicated by the primary cell culture of miR-122a-TG epithelium (MCE-TG, Fig. 3 D-F).

MiR-122a enhanced the intestinal permeability and inflammation in vitro and in vivo

The body weight of miR-122a-TG mice was significantly less than that of the control at 8 and 12 weeks. $(\mathrm{P}<0.05$, Fig. $5 \mathrm{~A}) \mathrm{A}$ high mortality of the miR-122a-TG mice was observed. The TER was significantly lower after transfection of miR-122a into Caco-2 cells, whereas the relative intensity was significantly higher $(\mathrm{P}<0.05$, Fig. $4 \mathrm{~A})$. Ussing chamber assay and fractional excretion (for lactulose/mannitol) also showed a higher permeability of miR$122 \mathrm{a}-\mathrm{TG}$ mice compared with the control WT group. The qRT-PCR assays revealed that IL-6 and TNF- $\alpha$ expression at the mRNA levels of serum both significantly increased in the miR122a-TG mice relative to the WT group. ( $<<0.05$, Fig. 4B, C)

Clinical samples were also used to investigate the clinical feature of miR-122a. Fresh colon tissues of IBD and paired adjacent normal colon tissues were collected to determine tissue mR-122a expression level by qRT-PCR. The levels of miR-122a of the colon tissues of IBD were significantly higher than those of paired adjacent normal colon tissues. $(\mathrm{P}<0.05$, Fig. 5D) The zonulin expression at the mRNA levels increased in the colon tissues of IBD relative to that of paired adjacent normal colon tissues. ( $P<0.05$, Fig. $5 \mathrm{E}$ ) The IL- 6 and TNF- $\alpha$ levels in serum detected by ELISA kit (RayBiotech, USA) were increased in IBD patients than in healthy volunteers. $(\mathrm{P}<0.05$, Fig. 5F, G)

\section{Discussion}

Intestinal barrier mainly consists of complete intestinal epithelial cells [23], with tight junction between the adjacent cells $[24,25]$. Human intestine faces with the highest bacterial load, approximately more than 500 different types of microorganisms [26]. Therefore, we aim to investigate the relationship between microRNA and intestinal barrier function.

TNF- $\alpha$ could increase the expression of miR-122a in enterocytes, cultured cells, and intestinal tissue and thus induce degradation of occludin mRNA and increase the intestinal permeability [11]. By contrast, zonulin could be an indicator of intestinal barrier, which was initially discovered in 2000 as the target of zonula occludens toxin [12]. Our previous study indicated that the infection rate after peri-operative treatment of probiotics was lower than that of the control group [12]. Probiotics could decrease the serum zonulin, the duration of postoperative pyrexia, the duration of antibiotic therapy, and the rate of postoperative infectious complications [12]. Our present study aimed to investigate the molecular regulatory mechanism of miR-122a on the expression level of zonulin for treating intestinal barrier dysfunction. LPS was shown to be an injury factor on intestinal barrier [27], and we first verified the effects of LPS on the expression level of zonulin and miR122a. The results indicated that the expression levels of miR-122a and zonulin were both increased after treating LPS. However, the expression level of EGFR was only decreased in the protein expression level, rather than the mRNA level determined by qRT-PCR, due to a posttranscript regulation of EGFR, such as regulated by miR-122a. MiR-122a-TG mice and the primary intestinal cell culture could further verify the regulatory effects of miR-122a on EGFR expression. MiR-122a might also be a regulator of intestinal barrier.

The luciferase assay verified EGFR as the target of miR-122a. The transfection of miR122a into the Caco-2 cells led to a decreased expression of EGFR only in the protein level determined by Western blot, which was inhibited at the posttranscript level, whereas the mRNA of EGFR was unaffected, as a regulatory mechanism of microRNA $[1,15,28]$. The cotranscription of EGFR with miR-122a could cover the effects of miR-122a on the increased expression level of zonulin possibly because the increased EGFR maintained the molecular regulatory inhibition on the expression of zonulin. Conversely, miR-122a could elicit its effects by inhibiting EGFR transcription. 


\section{Cellular Physiology Cell Physiol Biochem 2017;42:848-858 \begin{tabular}{l|l} 
DOI: 10.1159/000478629 & Ond Biochemistry 2017 The Author(s). Published by S. Karger AG, Basel \\
wubw.karger.com/cpb
\end{tabular} \\ Zhang et al.: MiR-122a, Zonulin and Intestinal Barrier}

The intestinal permeability was increased after the miR-122a overexpression and in the miR-122a-TG group, which was paralleled with the zonulin level, and this increase could be an indicator of intestinal permeability, as reported [12]. The inflammatory cytokines of IL-6 and TNF- $\alpha$ were also paralleled with the expression level of miR-122a. Therefore, we deduced that LPS could stimulate the expression of miR-122a and consequently inhibit the post-transcript expression of EGFR, increase expression, and promote intestinal permeability and intestinal inflammation (LPS-miR122a-EGFR-zonulin-intestinal permeability-inflammation). We supposed that LPS could induce intestinal barrier dysfunction via the miR-122a pathway.

In the molecular mechanism of miR-122a, miR-122 regulates the synthesis of the protein CAT-1; mRNA is targeted to $\mathrm{P}$ bodies, which can be relieved by the protein $\mathrm{HuR}$, released from the nucleus under stress conditions [29]; HuR interaction leads to the release of the mRNA from the P bodies [29]. Numerous other targets, such as CD320, AldoA, and BCKDK, have also been identified by microarray of changes in the liver of the mice treated with miR-122 inhibitors [30-32]. Other reports have shown that miR-122 can also regulate systemic iron homeostasis by Hjv and Hfe [33], whereas inhibition of miR-122 in mice or primates does not result in any detectable liver toxicity [34]. The molecular mechanism of miR-122a, especially for zonulin, has not been reported. Our study investigated the molecular mechanism of miR-122a on the expression of zonulin through the pathway of EGFR, which is a cell surface receptor for members of the epidermal growth factor family of extracellular protein ligands [35]. Most studies on miR-122a have focused on hepatocellular carcinoma [36], which could reduce the tumorigenic properties in HCC cell lines, and it functions as a tumor suppressor gene and increases the response to the chemotherapeutic drugs sorafenib [37]. Several miR122 target genes have been identified, including ADAM10, IGF1R, CCNG1, and ADAM17 [37, 38]. Therefore, other signal transduction pathways also need further study. In our study, we mainly paid attention to the EGFR pathway, which could be regulated by miR-122a, thus leading to the alternation of zonulin. The molecular target, such as miR-122a, EGFR, and zonulin could be all used as potential therapeutic targets.

Our study might be limited by our insufficient investigations on the relationship between zonulin and tight-junction-associated proteins. Further tests may be essential for our future studies.

\section{Conclusion}

miR-122a could function as a positive factor of zonulin by targeting EGFR, which enhances intestinal epithelial permeability in vivo and in vitro.

\section{Acknowledgments}

This work was financially supported by National Natural Science Foundation of China (No. 81370480, 81670480), Training Program of the Major Research Plan of the Natural Science Foundation of Guangdong Province (2014A030308004), and High level talents in Guangdong Province special support plan - Youth Science and technology innovation talents (2015TQ01R334).

\section{Disclosure Statement}

The authors have declared that no conflict of interest exists. 


\section{Cellular Physiology Cell Physiol Biochem 2017;42:848-858 \begin{tabular}{l|l} 
DOI: 10.1159/000478629 & $\begin{array}{l}\text { O 2017 The Author(s). Published by S. Karger AG, Basel } \\
\text { www.karger.com/cpb }\end{array}$ \\
\hline
\end{tabular} \\ Zhang et al.: MiR-122a, Zonulin and Intestinal Barrier}

\section{References}

1 Cha ST, Tan CT, Chang CC, Chu CY, Lee WJ, Lin BZ, Lin MT, Kuo ML: G9a/RelB regulates self-renewal and function of colon-cancer-initiating cells by silencing Let-7b and activating the K-RAS/beta-catenin pathway. Nat Cell Biol 2016;18:993-1005.

2 Farh KK, Grimson A, Jan C, Lewis BP, Johnston WK, Lim LP, Burge CB, Bartel DP: The widespread impact of mammalian MicroRNAs on mRNA repression and evolution. Science 2005;310:1817-1821.

-3 He L, Thomson JM, Hemann MT, Hernando-Monge E, Mu D, Goodson S, Powers S, Cordon-Cardo C, Lowe SW, Hannon GJ, Hammond SM: A microRNA polycistron as a potential human oncogene. Nature 2005;435:828833.

-4 O'Donnell KA, Wentzel EA, Zeller KI, Dang CV, Mendell JT: c-Myc-regulated microRNAs modulate E2F1 expression. Nature 2005;435:839-843.

-5 Lu J, Getz G, Miska EA, Alvarez-Saavedra E, Lamb J, Peck D, Sweet-Cordero A, Ebert BL, Mak RH, Ferrando AA, Downing JR, Jacks T, Horvitz HR, Golub TR: MicroRNA expression profiles classify human cancers. Nature 2005;435:834-838.

6 Chen JF, Murchison EP, Tang R, Callis TE, Tatsuguchi M, Deng Z, Rojas M, Hammond SM, Schneider MD, Selzman CH, Meissner G, Patterson C, Hannon GJ, Wang DZ: Targeted deletion of Dicer in the heart leads to dilated cardiomyopathy and heart failure. Proc Natl Acad Sci USA 2008;105:2111-2116.

7 Huang Z, Shi T, Zhou Q, Shi S, Zhao R, Shi H, Dong L, Zhang C, Zeng K, Chen J, Zhang J: miR-141 Regulates colonic leukocytic trafficking by targeting CXCL12beta during murine colitis and human Crohn's disease. Gut 2014;63:1247-1257.

-8 Law IK, Bakirtzi K, Polytarchou C, Oikonomopoulos A, Hommes D, Iliopoulos D, Pothoulakis C: Neurotensin-regulated miR-133alpha is involved in proinflammatory signalling in human colonic epithelial cells and in experimental colitis. Gut 2015;64:1095-1104.

-9 Zhou Q Souba WW, Croce CM, Verne GN: MicroRNA-29a regulates intestinal membrane permeability in patients with irritable bowel syndrome. Gut 2010;59:775-784.

10 Ye D, Guo S, Al-Sadi R, Ma TY: MicroRNA regulation of intestinal epithelial tight junction permeability. Gastroenterology 2011;141:1323-1333.

11 McKenna LB, Schug J, Vourekas A, McKenna JB, Bramswig NC, Friedman JR, Kaestner KH: MicroRNAs control intestinal epithelial differentiation, architecture, and barrier function. Gastroenterology 2010;139:1654-1664, 1664 e1651.

12 Liu ZH, Huang MJ, Zhang XW, Wang L, Huang NQ, Peng H, Lan P, Peng JS, Yang Z, Xia Y, Liu WJ, Yang J, Qin HL, Wang JP: The effects of perioperative probiotic treatment on serum zonulin concentration and subsequent postoperative infectious complications after colorectal cancer surgery: a double-center and double-blind randomized clinical trial. Am J Clin Nutr 2013;97:117-126.

13 Tripathi A, Lammers KM, Goldblum S, Shea-Donohue T, Netzel-Arnett S, Buzza MS, Antalis TM, Vogel SN, Zhao A, Yang S, Arrietta MC, Meddings JB, Fasano A: Identification of human zonulin, a physiological modulator of tight junctions, as prehaptoglobin-2. Proc Natl Acad Sci USA 2009;106:16799-16804.

14 Munesue S, Kusano Y, Oguri K, Itano N, Yoshitomi Y, Nakanishi H, Yamashina I, Okayama M: The role of syndecan-2 in regulation of actin-cytoskeletal organization of Lewis lung carcinoma-derived metastatic clones. Biochem J 2002;363:201-209.

15 Chu VT, Graf R, Wirtz T, Weber T, Favret J, Li X, Petsch K, Tran NT, Sieweke MH, Berek C, Kuhn R, Rajewsky K: Efficient CRISPR-mediated mutagenesis in primary immune cells using CrispRGold and a C57BL/6 Cas 9 transgenic mouse line. Proc Natl Acad Sci USA 2016;113:12514-12519.

16 Saam JR, Gordon JI: Inducible gene knockouts in the small intestinal and colonic epithelium. J Biol Chem 1999;274:38071-38082.

17 Evans GS, Flint N, Somers AS, Eyden B, Potten CS: The development of a method for the preparation of rat intestinal epithelial cell primary cultures. J Cell Sci 1992;101(Pt 1):219-231.

18 Liu Z, Kang L, Li C, Tong C, Huang M, Zhang X, Huang N, Moyer MP, Qin H, Wang J: Knockout of MIMP protein in lactobacillus plantarum lost its regulation of intestinal permeability on NCM460 epithelial cells through the zonulin pathway. BMC Gastroenterol 2014;14:171.

19 Lewis BP, Shih IH, Jones-Rhoades MW, Bartel DP, Burge CB: Prediction of mammalian microRNA targets. Cell 2003;115:787-798. 


\section{Cellular Physiology Cell Physiol Biochem 2017;42:848-858 \begin{tabular}{l|l} 
DOI: 10.1159/000478629 & $\begin{array}{l}\text { O 2017 The Author(s). Published by S. Karger AG, Basel } \\
\text { www.karger.com/cpb }\end{array}$
\end{tabular} \\ Zhang et al.: MiR-122a, Zonulin and Intestinal Barrier}

20 Krek A, Grun D, Poy MN, Wolf R, Rosenberg L, Epstein EJ, MacMenamin P, da Piedade I, Gunsalus KC, Stoffel M, Rajewsky N: Combinatorial microRNA target predictions. Nat Genet 2005;37:495-500.

21 Sethupathy P, Megraw M, Hatzigeorgiou AG: A guide through present computational approaches for the identification of mammalian microRNA targets. Nat Methods 2006;3:881-886.

-22 Yan F, Cao H, Cover TL, Washington MK, Shi Y, Liu L, Chaturvedi R, Peek RM, Jr., Wilson KT, Polk DB: Colonspecific delivery of a probiotic-derived soluble protein ameliorates intestinal inflammation in mice through an EGFR-dependent mechanism. J Clin Invest 2011;121:2242-2253.

23 Han C, Ding Z, Shi H, Qian W, Hou X, Lin R: The Role of Probiotics in Lipopolysaccharide-Induced Autophagy in Intestinal Epithelial Cells. Cell Physiol Biochem 2016;38:2464-2478.

-24 Liu ZH, Kang L, Wang JP: Basic and clinical research on the regulation of the intestinal barrier by Lactobacillus and its active protein components: a review with experience of one center. Mol Biol Rep 2014;41:8037-8046.

25 Odenwald MA, Turner JR: The intestinal epithelial barrier: a therapeutic target? Nat Rev Gastroenterol Hepatol 2017;14:9-21.

26 Guyton K, Alverdy JC: The gut microbiota and gastrointestinal surgery. Nat Rev Gastroenterol Hepatol 2017;14:43-54.

27 Luissint AC, Parkos CA, Nusrat A: Inflammation and the Intestinal Barrier: Leukocyte-Epithelial Cell Interactions, Cell Junction Remodeling, and Mucosal Repair. Gastroenterology 2016;151:616-632.

-28 Koukos G, Polytarchou C, Kaplan JL, Morley-Fletcher A, Gras-Miralles B, Kokkotou E, Baril-Dore M, Pothoulakis C, Winter HS, Iliopoulos D: MicroRNA-124 regulates STAT3 expression and is down-regulated in colon tissues of pediatric patients with ulcerative colitis. Gastroenterology 2013;145:842-852 e842.

-29 Bhattacharyya SN, Habermacher R, Martine U, Closs EI, Filipowicz W: Relief of microRNA-mediated translational repression in human cells subjected to stress. Cell 2006;125:1111-1124.

-30 Krutzfeldt J, Rajewsky N, Braich R, Rajeev KG, Tuschl T, Manoharan M, Stoffel M: Silencing of microRNAs in vivo with 'antagomirs'. Nature 2005;438:685-689.

31 Esau C, Davis S, Murray SF, Yu XX, Pandey SK, Pear M, Watts L, Booten SL, Graham M, McKay R, Subramaniam A, Propp S, Lollo BA, Freier S, Bennett CF, Bhanot S, Monia BP: miR-122 regulation of lipid metabolism revealed by in vivo antisense targeting. Cell Metab 2006;3:87-98.

-32 Elmen J, Lindow M, Silahtaroglu A, Bak M, Christensen M, Lind-Thomsen A, Hedtjarn M, Hansen JB, Hansen HF, Straarup EM, McCullagh K, Kearney P, Kauppinen S: Antagonism of microRNA-122 in mice by systemically administered LNA-antimiR leads to up-regulation of a large set of predicted target mRNAs in the liver. Nucleic Acids Res 2008;36:1153-1162.

-33 Castoldi M, Vujic Spasic M, Altamura S, Elmen J, Lindow M, Kiss J, Stolte J, Sparla R, D'Alessandro LA, Klingmuller U, Fleming RE, Longerich T, Grone HJ, Benes V, Kauppinen S, Hentze MW, Muckenthaler MU: The liver-specific microRNA miR-122 controls systemic iron homeostasis in mice. J Clin Invest 2011;121:1386-1396.

-34 Elmen J, Lindow M, Schutz S, Lawrence M, Petri A, Obad S, Lindholm M, Hedtjarn M, Hansen HF, Berger U, Gullans S, Kearney P, Sarnow P, Straarup EM, Kauppinen S: LNA-mediated microRNA silencing in nonhuman primates. Nature 2008;452:896-899.

-35 Herbst RS: Review of epidermal growth factor receptor biology. Int J Radiat Oncol Biol Phys 2004;59:21-26.

-36 Tsai WC, Hsu SD, Hsu CS, Lai TC, Chen SJ, Shen R, Huang Y, Chen HC, Lee CH, Tsai TF, Hsu MT, Wu JC, Huang HD, Shiao MS, Hsiao M, Tsou AP: MicroRNA-122 plays a critical role in liver homeostasis and hepatocarcinogenesis. J Clin Invest 2012;122:2884-2897.

-37 Lynch TJ, Bell DW, Sordella R, Gurubhagavatula S, Okimoto RA, Brannigan BW, Harris PL, Haserlat SM, Supko JG, Haluska FG, Louis DN, Christiani DC, Settleman J, Haber DA: Activating mutations in the epidermal growth factor receptor underlying responsiveness of non-small-cell lung cancer to gefitinib. $\mathrm{N}$ Engl J Med 2004;350:2129-2139.

38 Jost M, Kari C, Rodeck U: The EGF receptor - an essential regulator of multiple epidermal functions. Eur J Dermatol 2000;10:505-510. 